\title{
Performance Forecasting of Share Market using Machine Learning Techniques: A Review
}

\author{
Sachin Kamley ${ }^{1}$, Shailesh Jaloree ${ }^{2}$, R. S. Thakur ${ }^{3}$ \\ ${ }^{1}$ Department of Computer Applications, S.A.T.I., Vidisha, India \\ ${ }^{2}$ Department of Applied Math's \& Computer Science, S.A.T.I., Vidisha, India \\ ${ }^{3}$ Department of Computer Applications, M.A.N.I.T., Bhopal, India
}

\begin{tabular}{l} 
Article Info \\
\hline Article history: \\
Received Aug 20, 2016 \\
Revised Nov 12, 2016 \\
Accepted Nov 26, 2016 \\
\hline
\end{tabular}

Keyword:

Machine learning

Performance forecasting

Share market

\begin{abstract}
Forecasting share performance becomes more challenging issue due to the enormous amount of valuable trading data stored in the stock database. Currently, existing forecasting methods are insufficient to analyze the share performance accurately. There are two main reasons for that: First, the study of existing forecasting methods is still insufficient to identify the most suitable methods for share price prediction. Second, the lack of investigations made on the factors affecting the share performance. In this regard, this study presents a systematic review of the last fifteen years on various machine learning techniques in order to analyze share performance accurately. The only objective of this study is to provide an overview of the machine learning techniques that have been used to forecast share performance. This paper also highlights a how the prediction algorithms can be used to identify the most important variables in a share market dataset. Finally, we could have succeeded to analyze share performance effectively. It could bring benefits and impacts to researchers, society, brokers and financial analysts.
\end{abstract}

Copyright (C) 2016 Institute of Advanced Engineering and Science. All rights reserved.

\section{Corresponding Author:}

Sachin Kamley,

Departement of Computer Applications,

S.A.T.I.,

B.T.I. Road, Sherpura, Vidisha, 464001, MP. India.

Email:skamley@gmail.com

\section{INTRODUCTION}

Now a day, share price prediction is an important concern for policy makers, researchers and investors because accurate price prediction plays key role in investment decision making. In general, stock market nature is considered to be chaotic and complicated, but it has been influenced by several economic and external environmental factors. Therefore, share market analyses have been using some approaches for predicting share prices.

The random walk theory states that share price movements are independent of each other and price movements do not follow any patterns or trends [1]. Thus, it is practically impossible to predict the future price movements based on the historical data.

On the other hand, technical analysis can be used to identify the patterns and trends based on the historic prices [1]. So therefore, future price movements can be done by examining past share prices. For many years, technical analyses with statistical approaches have been widely applied to this area in order to develop some concepts and strategies to be helpful for share performance forecasting [1-2].

Currently, there are various techniques have been proposed to evaluate share performance. Machine learning is one of the core areas which has been widely used to analyze share performance. The main objective of machine learning techniques is to automatically learn and recognize patterns from huge amounts 
of data [3]. However, these patterns and trends can be helpful for predicting share performance effectively and assist financial analyst, investors and brokers to appropriate share selection.

So therefore, application of machine learning techniques in share market research can be addressed with different entities. In order to encounter the problem, a systematic review is proposed. Therefore, the main objectives of proposed review are:

1) To identify the research gaps in existing prediction methods.

2) To study and identify variables which affect share performance.

3) To study the existing prediction methods in order to analyze share performance.

The next section discusses the methodology of survey in predicting share performance. Section 3 discusses on important factors in predicting share performance. Section 4 discusses detail results on existing prediction methods and at last section 5 discusses conclusion and future scopes of study.

\section{RESEARCH METHOD}

In this context, the systematic relational review is to be done to find out suitable methods for existing parameters as well as to fulfills the goals in existing research and to place a new research activity in the suitable context [4]. The main aim of systematic review of the current literature is to support the proposed research questions. Next, subsections will be identifying the research questions to guide the results. This is very useful to identify the scope and objectives of the research study.

\subsection{Research Questions}

Research questions are very important criteria to understand the existing studies of forecasting share performance. The Kitchen hams steps are used for structuring the research questions which consist of Population, Intervention, Outcome and Context (PIOC) [4]. Table 1 shows the criteria of research questions.

Table 1. Research Questions Criteria

\begin{tabular}{cc}
\hline Criteria & Descriptions \\
\hline Population & Stock Market Dataset \\
Intervention & Methods/Techniques for Prediction \\
Outcome & Prediction Accuracy, Successful Prediction \\
Techniques & Thtext \\
& $\begin{array}{c}\text { Individual Share Performance, All Types of Empirical } \\
\text { Studies such as Case Study, Questionnaires, Surveys } \\
\text { and Experiments. }\end{array}$ \\
\hline
\end{tabular}

In this study, therefore two basic research questions are proposed.

Q1: what are the important variables used in forecast share performance?

Q2: what are the prediction methods used for evaluation of share performance?

Before going to the depth of the study the next subsection discusses search strategy for conducting review purpose. The main concern of this study is to investigate the appropriateness of the research questions with the objectives of the study.

\subsection{Search Strategy}

A well planned search strategy plays very important role in a systematic review because every relevant piece of work can be found in the search results. Therefore, an extensive research for research papers was conducted to try answering the proposed research questions. In order to identify published articles on machine learning techniques which were specifically applied in either hybrid or individual form to predict share prices. In this study, the literature search covered the period of publications from 2000 to 2015. However, the online search was based on such keywords as decision tree, neural network, support vector machine, genetic algorithm, Bayesian network, etc. and each of the keyword is attached with share price prediction. Moreover, the total 100 articles published over the period, but only 71 relevant publications in literature review could be identified. Table 2 shows a description of research literature which were identified through online search. 
Table 2. Description of Search Databases

\begin{tabular}{cc}
\hline S.No. & Data Base \\
\hline 1 & Science Direct \\
2 & Scopus \\
3 & Springer \\
4 & Google Scholar \\
5 & IEEE Xplore \\
6 & Microsoft Academy Search \\
7 & Web of Science \\
8 & DOAJ \\
9 & ProQuest \\
10 & Taylors \& Francis \\
\hline
\end{tabular}

\section{IMPORTANT FACTORS ON PREDICTING SHARE MARKET PERFORMANCE}

This section mainly highlights the important factors in predicting share market performance. There are two key factors in predicting share performances which are variables and prediction methods. Therefore, the next subsections will be focused on the important variables and prediction methods used in stock market study.

\subsection{The Important Variables Used in Predicting Share Performance}

In this study, the systematic review is used to identify the important variables in predicting share performance. In general, the variables that have been frequently used by researchers which are fundamental, technical, macro economical and lagged index. Twelve of the thirty papers have used price earnings ratio, earnings per share, Net Asset Value, General Index (GI), share volume, price per annum, book value, face value, financial status of company, stock buy/sell news, dividend yield, treasury bill rate, current ratio, financial leverage ratio, income statement, revenue growth, Growth in net sales, Growth in net profit, Return on Equity, Net Profit Margin (NPM), Price/Sales ratio etc. as their main attributes to predict share market performance [5-19]. The main purpose of using these variables is because it deals with the value of the company stock with regards to its potential growth in future earnings. It can also be considered as an indication of realizing share growth potential [1], [6], [17].

Next, the most often variables used by researchers are technical indicators. The technical indicator includes Moving Average (MA), Exponential Moving Average (EMA), Relative Strength Index (RSI) and Moving Average Convergence Divergence (MACD), Bollinger Bands, Stochastic Oscillator, Momentum, slow \%D, William R\%, Price Rate of Change (ROC), Disparity (5-10), Price Oscillator (OSCP), Commodity Channel Index (CCI), Price and Volume Trend (PVT), On Balance Volume (OBV), Mass Index (MI), Average True Range (ATR), Momentum, Chaikin Money Flow (CMF), etc. [2], [6], [12-13], [20-37]. The main idea behind using these indicators is to evaluate stock price movements based on historical price patterns and volumes.

Most of the researchers have also used macroeconomic indicators for evaluating share performance. These variables include short term and long term interest rates, inflation rate, Foreign Direct Investment (FDI), unemployment rate, Gross Domestic Product (GDP), Consumer Price Index (CPI), Industrial Production (IP), Government Consumption (GC), Private Consumption (PC), Gross National Product (GNP), Money Supply, Oil Prices, Exchange Rates etc. [13], [22], [27], [39-48].

\subsection{The Prediction Methods Used for Share Performance}

In the share market, predictive modeling is usually used to predict share performance. In order to build predictive modeling, there are several machine learning techniques are used which are neural network, support vector machine and genetic algorithm, etc. to cover all machine learning algorithms is not possible so we have used few popular algorithms such as decision tree, support vector machine, neural network, genetic algorithm, Bayesian network for share price prediction. The next subsection describes the application of these algorithms in detail.

\subsubsection{Decision Tree}

The decision tree is one of the well known classification algorithms used in data mining and machine learning to create knowledge structures that guide the decision making process [12-13]. For the couple of years various researchers have used this technique due to its simplicity and capability to uncover small or large data samples and predict the value. Therefore, there are approximately ten (11) papers that have used a decision tree algorithm to evaluate share performance. Table 3 shows a description of the decision tree technique as selected by most of the authors for share forecasting. 
Table 3. Performance Accuracy of Decision Tree Method

\begin{tabular}{lcc}
\hline \multicolumn{1}{c}{ Method } & Results & Authors \\
\hline Decision Tree & $85.94 \%$ & Chang [6] \\
Decision Tree & $81 \%$ & Shaifee et al. [7] \\
Decision Tree & $71 \%$ & Gepp et al. [9] \\
Decision Tree & $81 \%$ & Wu et al. [10] \\
Hybrid Decision Tree & $86 \%$ & Tsai et al.[11] \\
Decision Tree & $82 \%$ & Ren et al. [12] \\
Decision Tree & $65.41 \%$ & Tsai et al. [13] \\
Hybrid Decision Tree & $88 \%$ & Wang et al. [26] \\
Decision Tree & $85.71 \%$ & Chen et al. [17] \\
Decision Tree & $73.60 \%$ & Kirkos et al. [18] \\
Hybrid Decision Tree & $80.24 \%$ & Barak et al. [19] \\
\hline
\end{tabular}

\subsubsection{Neural Network (NN)}

Neural Network is another most popular technique which has been extensively used for share price prediction. The advantage of using $\mathrm{NN}$ is that it has the capability to represent or modelling complex nonlinear input/output relationships. However, the NN system composed of many simple processing elements operating in parallel whose function is determined by the network structure, connection strengths, and the processing performed at computing elements or nodes [49]. In this study, NN is selected as one of the best prediction method. Though, the meta-analysis study ten (10) papers have been used NN for share price prediction. Table 4 shows the description of the $\mathrm{NN}$ technique as selected by most of the authors for share forecasting.

Table 4. Performance Accuracy of NN Method

\begin{tabular}{lcc}
\hline \multicolumn{1}{c}{ Method } & Results & Authors \\
\hline Neural Network & $71 \%$ & Phua et al. [2] \\
Hybrid Dynamic ANN & $96 \%$ & Bisoi et al. [20] \\
Neural Network & $91 \%$ & Masod [50] \\
Neural Network & $90 \%$ & Olatunji et al. [21] \\
Hybrid Model & $76.06 \%$ & Huang et al. [43] \\
(BPNN+SVM+C4.5+LR+KNN) & $59.38 \%$ & Bola et al. [30] \\
Neural Network & $87.50 \%$ & Olivera et al. [31] \\
Neural Network & $76 \%$ & Cheng et al. [32] \\
Hybrid Model & $75 \%$ & Tsai et al. [49] \\
(PNN+C4.5+Rough Set) & $88.84 \%$ & Lahmiri [51] \\
Multi Layer Perceptron (MLP) & & \\
PNN with Strategy &
\end{tabular}

\subsubsection{Support Vector Machine (SVM)}

Support Vector Machine (SVM) is another well known machine learning techniques used for data classification based on statistical theory. It is a supervised learning algorithm and initially it was designed to solve pattern recognition problems, but it has rendered to solve non -linear regression problems as well [23], [52]. Table 5 shows the description of the SVM technique as selected by most of the authors for share forecasting.

Table 5. Performance Accuracy of SVM Method

\begin{tabular}{lcc}
\hline \multicolumn{1}{c}{ Method } & Results & Authors \\
\hline SVM & $79.40 \%$ & Chandwani et al. [23] \\
SVM with Macroeconomic & $64 \%$ & Lahmiiri [51] \\
SVM & $73 \%$ & Huanga et al. [53] \\
SVM & $64.75 \%$ & Kim [52] \\
Hybrid SVM with GA & $61.73 \%$ & Choudhary et al. [54] \\
Hybrid SVM with GA & $96.46 \%$ & Khatibi et al. [55] \\
SVM & $91 \%$ & Cao. et al. [56] \\
Hybrid SVM with SOM & $80.26 \%$ & Cao et al. [57] \\
SVM & $72 \%$ & Sapankevych et al. [58] \\
SVM (Polynomial) & $84.40 \%$ & Timor et al. [59] \\
\hline
\end{tabular}




\subsubsection{Genetic Algorithms (GAs)}

Genetic Algorithms are general purpose adaptive heuristic search techniques based on the mechanisms of natural selection and genetics. However, the main idea of GAs is to start with a population of solutions to a problem and attempt to produce new generations of solutions which are better than the previous ones [3]. GAs requires only fitness information, not gradient information or other internal knowledge of a problem. GAs has traditionally been used in optimization but, with a few enhancements, can perform classification and prediction as well [3], [60]. Table 6 shows the description of the GAs technique as selected by most of the authors for share forecasting.

Table 6. Performance Accuracy of GAs Method

\begin{tabular}{lcc}
\hline \multicolumn{1}{c}{ Method } & Results & Authors \\
\hline GA with ANN & $94 \%$ & Jadav et al. [25] \\
Hybrid GA with SVM & $84.57 \%$ & Yu et al. [61] \\
GA & $97 \%$ & Sheta et al. [62] \\
Hybrid GA-RBF & $85 \%$ & Majhi et al. [63] \\
GA & $95 \%$ & Samant [60] \\
GA & $95 \%$ & Wei [64] \\
GA & $77.84 \%$ & Sexton et al. [65] \\
GA with GMDH Type & $94 \%$ & Fallahi et al. [66] \\
Hybrid GA & $93 \%$ & Hassan et al. [67] \\
\hline
\end{tabular}

\subsubsection{Bayesian Network (BN)}

Bayesian Network $(\mathrm{BN})$ has gained so much popularity in finance as modelling tools having ability to solve complex problems involving the probabilistic analysis under uncertainty. $\mathrm{BN}$ is probabilistic graphical models that represent a set of random variables for a given problem, and used to represent the probabilistic relationship between them [30], [68]. However, the BN structure can be used to predict the possibility of rising or falling market index or stock prices over time. Table 7 shows the description of the $\mathrm{BN}$ technique as selected by most of the authors for share forecasting. Figure 1 shows prediction accuracy of algorithms since 2000-2015.

Table 7. Performance Accuracy of BN Method

\begin{tabular}{lcc}
\hline \multicolumn{1}{c}{ Method } & Results & Authors \\
\hline DBN & $89 \%$ & Wang et al. [26] \\
BN & $78.13 \%$ & Bola et al. [30] \\
BN & $92 \%$ & Naslmosavi et al. [69] \\
BN & $60 \%$ & Zuo et al. [67] \\
BN & $82.46 \%$ & Kita et al. [37] \\
BN & $76 \%$ & Bogle et al. [70] \\
BN $^{\prime}$ & $86 \%$ & Patel et al. [71] \\
\hline
\end{tabular}

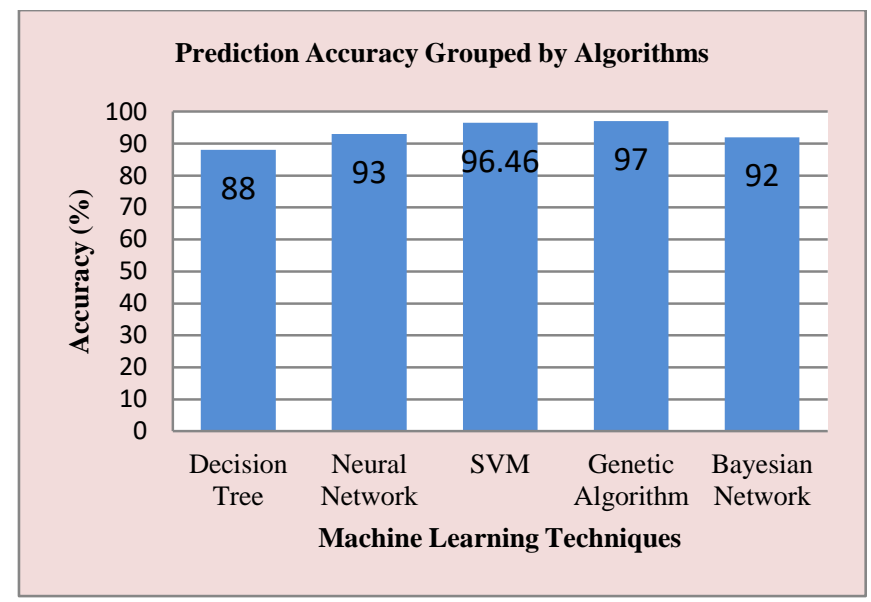

Figure 1. Prediction Accuracy Grouped by Algorithms Since 2000-2015 


\section{DISCUSSION}

In this section, we will discuss the result analysis of recent works in predicting share performance. This research study mainly based on the highest accuracy of prediction methods and also the most important factors that may influence the share performance. Figure 1 clearly states that the genetic algorithm (GA) method has the highest prediction accuracy by $(97 \%)$ followed by Support Vector Machine (SVM) by (96.46\%). Next, Neural Network (NN) has the 96\% prediction accuracy which is slightly lower than SVM method. Next, Bayesian Network (BN) has the 92\% prediction accuracy. Lastly, the method that has lowest prediction accuracy is a decision tree by (88\%). However, the results on prediction accuracy are depending on the variables or features that were used during the prediction process.

GA method gave the highest prediction accuracy. The main attributes used during the prediction process are fundamental variables which are 1 year Treasury Bill Yield, the earnings per share, dividend per share for the S\&P 500 and the current week's S\&P 500 [25]. Next, SVM method has the second highest prediction accuracy which used the technical parameters as prediction process. The main parameters of SVM method are Momentum, Williams's \%R, Rate of Change (ROC), 5 day disparity, 10 day disparity, Stochastic $\% \mathrm{~K}$ and Price Volume Trend (PVT) [51], [53], [59]. Next is a NN method with the performance accuracy around (96\%). The main parameters used during the prediction process are Moving Average (MA), stochastic line, WMS\%R indicator (R-index) and 25 -65 days lagged index data as technical indicators [51]. Next is the BN method with the performance accuracy around (92\%). The parameters used during the prediction process are fundamental parameters are liquidity ratios, leverage ratios, profitability ratios and other factors like firm's size and the auditor's opinion. Others, parameters are used during the BN prediction process is daily up- down on the stock index on the next day as taken as random variables for the BN model [68].

Lastly, the method has the lowest prediction accuracy is a Decision Tree (DT) by (88\%). The variables used are income statement of the last two years, export growth rate, import growth rate, earning after tax margin, current ratio, Moving Average (MA), Relative Strength Index (RSI), Exponential Moving Average (EMA), long term interest rates, and Gross Domestic Product (GDP) etc [48]. However, these attributes are also used among all prediction methods, but the result showed that DT method gave highest prediction accuracy as compared to other methods. This is because for short term forecasting DT method performs outstanding and variables used are significant with each other when the DT model using as a prediction process.

\section{CONCLUSION AND FUTURE SCOPES}

Share price forecasting is an important issue in finance because it will be motivating investors and brokers to invest money in the market. This research study mainly reviewed previous studies on forecasting share performance with various prediction methods and study reveals that most of the researchers have used technical parameters as prediction process. Others have used fundamental and macroeconomic parameters as prediction process. Some researchers have also used lagged index variables as data set. Therefore, the prediction techniques GA, SVM and NN have been frequently used by researchers in the share market area. Based on the analysis, it is also observed that a hybrid model has a better prediction accuracy as compared to individual model.

At last, this research study will be motivated to carry out further research on share market problem as well as motivating the share users to monitor the share performance in a systematic way.

\section{REFERENCES}

[1] A. P. Das, "Security analysis and portfolio Management," I.K. International Publication, $3^{\text {rd }}$ Edition, New Delhi, India, 2008.

[2] P. K. Phua, et al., "Forecasting Stock Index Increments Using Neural Networks with Trust Region Methods," Proceedings of the International Joint Conference on Neural Networks, vol. 1, pp. 260-265, 2003.

[3] S. Rajasekaran, et al., "Neural Networks, Fuzzy Logic, and Genetic Algorithms Synthesis and Applications," PHI Learning Private Limited, $10^{\text {th }}$ Edition, New Delhi, India, 2008.

[4] B. Kitchenham, et al., "Systematic Literature Reviews in Software Engineering- A Tertiary Study," Inf. Softw. Technol., vol/issue: 52(8), pp.792-805, 2010.

[5] Z. H. Khan, et al., "Price Prediction of Share Market Using Artificial Neural Network (ANN)," International Journal of Computer Applications, vol/issue: 22(2), pp. 56-61, 2011.

[6] T. S. Chang, "A Comparative Study of Artificial Neural Networks and Decision Trees for Digital Game Content Stocks Price Prediction," Expert Systems with Applications, vol. 38, pp. 14846-14851, 2011.

[7] M. Shafiee, et al., "Forecasting Stock Returns Using Support Vector Machine and Decision Tree: A Case Study in Iran Stock Exchange," International Journal of Economy, Management and Social Sciences, vol/issue: 2(9), pp. 746-751, 2013. 
[8] P. C. Chang, et al., "An investigation of the Hybrid Forecasting Models for Stock Price Variation in Taiwan," Journal of the Chinese Institute of Industrial Engineering, vol/issue: 21(4), pp. 358-368, 2004.

[9] A. Gepp, et al., "Predicting Financial Distress: A Comparison of Survival Analysis and Decision Tree Techniques," Eleventh International Multi-Conference on Information Processing, 2015, IMCIP 2015. Procedia Computer Science, vol. 54, pp. 396 - 404, 2015.

[10] M. C. Wu, et al., "An Effective Application of Decision Tree to Stock Trading," Expert Systems with Applications, vol. 31, pp. 270-274, 2006.

[11] C. F. Tsai, et al., "Combining Multiple Feature Selection Methods for Stock Prediction: Union, intersection, and Multi Intersection Approaches,” Decision Support Systems, vol. 50, pp. 258-269, 2010.

[12] N. Ren, et al., "A Decision Tree based Classification Approach to Rule Extraction for Security Analysis," International Journal of Information Technology and Decision Making, vol/issue: 5(1), pp. 227-240, 2006.

[13] C. F. Tsai, et al., "Determinants of Intangible Assets Value: The Data Mining Approach," Knowledge Based Systems, vol. 31, pp. 67-77, 2012.

[14] S. H. Chun, et al., "Automated Generation of New Knowledge to Support Managerial Decision Making: Case Study in Forecasting a Stock Market," Expert Systems, vol/issue: 21(4), pp. 192-207, 2004.

[15] M. Karazmodeh, et al., "Stock Price Forecasting Using Support Vector Machines and Improved Particle Swarm Optimization," Journal of Automation and Control Engineering, vol/issue: 1(2), pp. 173-176, 2013.

[16] R. A. Rivera, et al., "Genetic Algorithms and Darwinian Approaches in Financial Applications: A survey," Expert Systems with Applications, vol/issue: 42(21), pp. 7684-7697, 2015.

[17] S. Chen, et al., "A Hybrid Approach of Stepwise Regression, Logistic Regression, Support Vector Machine, and Decision Tree for Forecasting Fraudulent Financial Statements," Scientific World Journal, pp. 1-9, 2014.

[18] S. Kirkos, et al., "Data Mining Techniques for the Detection of Fraudulent Financial Statements," Expert Systems with Applications, vol/issue: 32(4), pp. 995-1003, 2007.

[19] S. Barak, et al., "Developing an Approach to Evaluate Stocks by Forecasting Effective Features with Data Mining Methods," Expert Systems with Applications, vol. 42, pp. 1325-1339, 2015.

[20] R Bisoi, et al., "A Hybrid Evolutionary Dynamic Neural Network for Stock Market Trend Analysis and Prediction Using Unscented Kalman Filter," Applied Soft Computing, vol. 19, pp. 41-56, 2014.

[21] S. O. Olatunji, et al., "Forecasting the Saudi Arabia Stock Prices based on Artificial Neural Networks Model," International Journal of Intelligent Information Systems, vol/issue: 2(5), pp. 77-86, 2013.

[22] C. J. Huang, et al., "Application of Wrapper Approach and Composite Classifier to the Stock Trend Prediction," Expert Systems with Applications, vol. 34, pp. 2870-2878, 2008.

[23] D. Chandwani, et al., "Stock Direction Forecasting Techniques: An Empirical Study Combining Machine Learning System with Market Indicators in the Indian Context," International Journal of Computer Applications, vol/issue: 92(11), pp.78-84, 2014.

[24] A. Fan, et al., "Stock Selection Using Support Vector Machines," International Joint Conference on Neural Networks, Washington, IJCNN 2001. vol. 3, pp. 1793-1798, 2001.

[25] K. Jadav, et al., "Optimizing Weights of Artificial Neural Networks Using Genetic Algorithms," International Journal of Advanced Research in Computer Science and Electronics Engineering, vol/issue: 1(10), pp. 47-51, 2012.

[26] L. Wang, et al., "Stock Market Trend Prediction Using Dynamic Bayesian Factor Graph," Expert Systems with Applications, vol/issue: 42(15-16), pp. 6267-6275, 2015.

[27] T. H. Roh, "Forecasting the volatility of stock price index," Expert Systems with Applications: An International Journal, vol. 33, pp. 916-922, 2007.

[28] A. I. Diler, "Predicting Direction of ISE National-100 Index with Back Propagation Trained Neural Network," Journal of Istanbul Stock Exchange, vol/issue: 7(25), pp. 65-81, 2003.

[29] Y. Kara, et al., "Predicting Direction of Stock Price Index Movement Using Artificial Neural Networks and Support Vector Machines: The Sample of the Istanbul Stock Exchange," Expert Systems with Applications, vol. 38, pp. 5311-5319, 2011.

[30] A. A. Bola, et al., "Forecasting Movement of the Nigerian Stock Exchange All Share Index Using Artificial Neural and Bayesian Networks," Journal of Finance and Investment Analysis, vol/issue: 2(1), pp. 41-59, 2013.

[31] D. Oliveira, et al., "Applying Artificial Neural Networks to prediction of Stock Price and Improvement of the Directional Prediction Index- Case Study of PETR4, Petrobras, Brazil," Expert System with Applications, vol. 40, pp. 7596-7606, 2013.

[32] J. H. Cheng, et al., "A Hybrid Forecast Marketing Timing Model based on Probabilistic Neural Network (PNN), Rough set and C4.5," Expert Systems with Applications, vol. 37, pp. 1814-1820, 2010.

[33] L. G. Cao, et al., "Support Vector Machine with Adaptive Parameters in Financial Time Series Forecasting," IEEE Transactions on Neural Networks, vol/issue: 14(6), pp. 1506-1518, 2003.

[34] M. Karazmodeh, et al., "Stock Price Forecasting Using Support Vector Machines and Improved Particle Swarm Optimization," Journal of Automation and Control Engineering, vol/issue: 1(2), pp. 173-176, 2013.

[35] R. A. Rivera, et al., "Genetic Algorithms and Darwinian Approaches in Financial Applications: A survey," Expert Systems with Applications, vol/issue: 42(21), pp. 7684-7697, 2015.

[36] K. Kim, et al., "Genetic Algorithms Approach to Feature Discretization in Artificial Neural Networks for the Prediction of Stock Price Index," Expert Systems with Applications, vol/issue: 19(2), pp. 125-132, 2000.

[37] E. Kita, et al., "Application of Bayesian Network to Stock Price Prediction," Artificial Intelligence Research, vol/issue: 1(2), pp. 171-184, 2012. 
[38] C. F. Tsai, et al., "Stock Price Forecasting by Hybrid Machine Learning Techniques," Proceedings of the International Multi Conference of Engineers and Computer Scientists, Hong Kong, 2009, IMECS 2009, vol. 1, pp. 57-64, 2009.

[39] P. M. Tsang, et al., "Design and Implementation of NN5 for Hong Kong Stock Price Forecasting," Engineering Applications of Artificial Intelligence, vol. 20, pp. 453-461, 2007.

[40] S. R. Stansell, et al., "Forecasting the Direction of Change in Sector Stock Indexes: An Application of Neural Networks," Journal of Asset Management, vol/issue: 5(1), pp. 37-48, 2004.

[41] A. S. Chen, et al., "Application of Neural Networks to an Emerging Financial Market: Forecasting and Trading the Taiwan Stock Index," Comput.Oper. Res, vol/issue: 30(6), pp. 901-923, 2003.

[42] S. A. Hamid, et al., "Using Neural Networks for Forecasting Volatility of S\&P 500 Index Future Prices," Journal of Business Research, vol/issue: 57(10), pp. 1116-1125, 2004.

[43] W. Huang, et al., "Neural Networks in Finance and Economics Forecasting," International Journal of Information Technology and Decision Making, vol/issue: 6(1), pp. 113-140, 2007.

[44] R. T. Gonzalez, et al., "Ensemble System based on Genetic Algorithm for Stock Market Forecasting," IEEE Congress on Evolutionary Computation (CEC), Sendai, pp. 3102-3108, 2015.

[45] Q. Cao, et al., "Neural Network Earnings per Share Forecasting Models: A Comparison of Backward Propagation and the Genetic Algorithm," Decision Support Systems, vol/issue: 47(1), pp. 32-41, 2009.

[46] M. Hassan, "Stock Market Forecasting Using Hidden Markov Model: A New Approach," in IEEE Editor, Proceedings of the $5^{\text {th }}$ International Conference on Intelligent Systems Design and Applications, 2005.

[47] O. Jangmin, et al., "Stock Trading by Modelling Price Trend with Dynamic Bayesian Networks," in IDEAL, pp. 794-799, 2004.

[48] C. Y. Huang, et al., "Application of Integrated Data Mining Techniques in Stock Market Forecasting," Cogent Economics and Finance, vol/issue: 2(9295), pp. 1-18, 2014.

[49] C. F. Tsai, et al., "Determinants of Intangible Assets Value: The Data Mining Approach," Knowledge Based Systems, vol. 31, pp. 67-77, 2012.

[50] N. Masoud, "Predicting Direction of Stock Prices Index Movement Using Artificial Neural Networks: The Case of Libyan Financial Market,” British Journal of Economics, Management \& Trade, vol/issue: 4(4), pp. 597-619, 2014.

[51] S. Lahmiri, "A Comparison of PNN and SVM for Stock Market Trend Prediction Using Economic and Technical Information," International Journal of Computer Applications, vol/issue: 29(3), pp. 24-30, 2011.

[52] K. J. Kim, "Financial Time Series Forecasting Using Support Vector Machines," Neuro-computing, vol. 55, pp. 307-319, 2003.

[53] W. Huanga, et al., "Forecasting Stock Market Movement Direction with Support Vector Machines," Computers \& Operations Research, vol. 32, pp. 2513-2522, 2005.

[54] R. Choudhary, et al., "A Hybrid Machine Learning System for Stock Market Forecasting," International Journal of Computer, Electrical, Automation, Control and Information Engineering, vol/issue: 2(3), pp. 689-692, 2008.

[55] V. Khatibi, et al., "A New Support Vector Machine-Genetic Algorithm (SVMGA) based Method for Stock Market Forecasting," International Journal of the Physical Sciences, vol/issue: 6(25), pp. 6091-6097, 2011.

[56] L. G. Cao, et al., "Financial Forecasting Using Support Vector Machines," Neural Comput \& Applic, Springer, vol. 10, pp. 184-192, 2001.

[57] L. G. Cao, et al., "Improved Financial Time Series Forecasting by Combining Support Vector Machines with SelfOrganizing Feature Map," Intelligent Data Analysis, vol/issue: 5(4), pp. 339-354, 2001.

[58] N. I. Sapankevych, et al., "Time Series Prediction Using Support Vector Machines: A Survey," IEEE Computational Intelligence Magazine, vol/issue: 4(2), pp. 24-38, 2009.

[59] M. Timor, et al., "Performance Comparison of Artificial Neural Network (ANN) and Support Vector Machines (SVM) Models for the Stock Selection Problem: An Application on the Istanbul Stock Exchange (ISE) -30 Index in Turkey," African Journal of Business Management, vol/issue: 6(3), pp. 1191-1198, 2012.

[60] S. Samant, "Prediction of Financial Performance Using Genetic Algorithm and Associative Rule Mining," International Journal of Engineering Research and General Science, vol/issue: 3(1), pp. 1035-1045, 2015.

[61] L. Yu, et al., "Mining Stock Market Tendency Using GA- Based Support Vector Machines," LNCS (Springer), vol. 3828, pp. 336-345, 2005.

[62] A. F. Sheta, et al., "A Genetic Programming Model for S\&P 500 Stock Market Prediction," International Journal of Control and Automation, vol/issue: 6(5), pp. 303-314, 2013.

[63] B. Majhi, et al., "On the Development and Performance Evaluation of a Multi Objective GA-based RBF Adaptive Model for the Prediction of Stock Indices," Journal of King Saud University - Computer and Information Sciences, vol. 26, pp. 319-331, 2014.

[64] L. Y. Wei, "A Hybrid Model based on ANFIS and Adaptive Expectation Genetic Algorithm to Forecast TAIEX," Economic Modelling, vol. 33, pp. 893-899, 2013.

[65] R. S. Sexton, et al., "Comparative Evaluation of Genetic Algorithm and Backpropagation for Training Neural Networks," Information Sciences, vol/issue: 129(1), pp. 45-59, 2000.

[66] S. Fallahi, et al., "Applying GMDH-Type Neural Network and Genetic Algorithm for Stock Price Prediction of Iranian Cement Sector," Applications and Applied Mathematics: An International Journal (AAM), vol/issue: 6(2), pp. $572-591,2011$.

[67] M. R. Hassan, et al., "A Fusion Model of HMM, ANN and GA for Stock Market Forecasting," Expert Systems with Applications, vol/issue: 33(1), pp. 171-180, 2007.

[68] Y. Zuo, et al., "Up/Down Analysis of Stock Index by Using Bayesian Network," Engineering Management Research, vol/issue: 1(2), pp. 46-52, 2012.

Performance Forecasting of Share Market Using Machine Learning Techniques: A Review (Sachin Kamley) 
[69] S. Naslmosavi, et al., "Comparing the Ability of Bayesian Networks and Adaboost for Predicting Financial Distress of Firms Listed on Tehran Stock Exchange (TSE)," Australian Journal of Basic and Applied Sciences, vol/issue: 5(10), pp. 629-634, 2011.

[70] S. A. Bogle, et al., "A Machine Learning Predictive Model for the Jamaica Frontier Market," Proceedings of the World Congress on Engineering, WCE, London (U.K.), 2015.

[71] J. Patel, et al., "Predicting Stock and Stock Index Price Movement Using Trend Deterministic Data Preparation and Machine Learning Techniques,” Expert Systems with Applications, vol/issue: 42(1), pp. 259-268, 2015.

\section{BIOGRAPHIES OF AUTHORS}
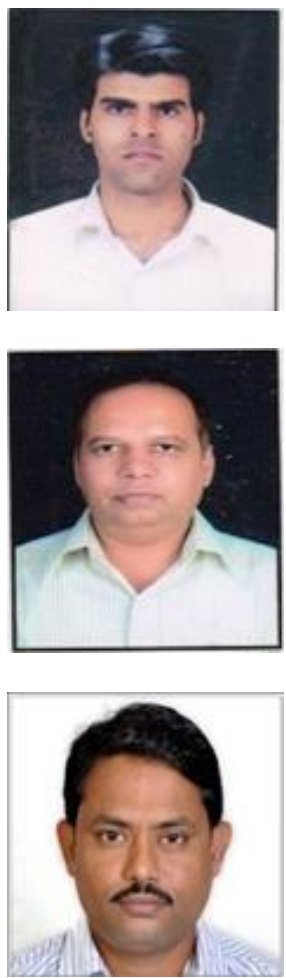

Sachin Kamley did his Masters from S.A.T.I., Computer Applications Department, Rajiv Gandhi Technological University, Bhopal (M.P.) in 2006. He is working at Samrat Ashok Technological Institute (S.A.T.I), Vidisha as a Lecturer from May 2007 to Department of Computer Applications and completed Ph.D. from Barkatullah University, Bhopal in the year 2015. He has attended many workshops and conferences of National repute.

Shailesh Jaloree is an Associate Professor in the Department of Applied Math's and Computer Science at Samrat Ashok Technological Institute (S.A.T.I.), Vidisha, India. He earned his Master Degree from Devi Ahiliya University Indore (M.P.) in 1991 and Ph.D. Degree (Applied Maths) From Barkatullah University, Bhopal (M.P.) in 2002. At Present he is guiding several Ph.D. Research Scholars in Mathematics and Computer Science field. He has published more than 35 Research Paper in National, International, Journals and Conferences. His areas of interest include Special Function, Data Mining, Data Warehousing and Web Mining.

Ramjeevan Singh Thakur is an Associate Professor in the Department of Computer Applications at Maulana Azad National Institute of Technology, Bhopal, India. He had a long carrier in teaching and research, including Three Year Teaching in the Department of Computer Applications at National Institute of Technology, Tiruchirapalli, and Tamilnadu, India. At Present he is guiding several Ph.D. Research Scholars and handling Government Research Projects of about Rs. One Crore. He has published more than 75 Research Paper in National, International, Journals and Conferences. He has visited several Universities in USA, Hong Kong, Iran, Thiland, Malaysia, and Singapore. 